\title{
Development of soil line and vegetative indices using spectroradiometer
}

S.S. RAUT AND B.K. GAVIT

Received : 28.11.2014; Revised : 23.08.2015; Accepted : 20.09.2015

See end of the Paper for authors' affiliation

Correspondence to :

\section{S.S. RAUT}

Department of Soil and Water Conservation Engineering, K.K. Wagh College of Agricultural Engineering and Technology, NASHIK (M.S.) INDIA
- ABSTRACT : One of the major applications of remote sensing in environmental resources management and decision making is the detection and quantitative assessment of soil and vegetation. Operational monitoring of vegetative cover by remote sensing currently involves the utilisation of vegetation indices (VI), it is the function of the reflectance in red (R) and near-infrared (NIR) spectral bands. Although many variations exist, most of them are the ratio of the reflection of light in the red and NIR sections of the spectrum to separate the landscape into water, soil, and vegetation. The present research was conducted for development of soil line and vegetation indices ratio vegetative index (RVI) and soil adjusted vegetative index (SAVI) and to develop relationship between vegetation indices and bulk density. Four soil series namely Gulvanch, Targaon, Rahuri and Pather series were used in the study. The soil line, a linear relationship between bare soil reflectance observed in two IR and NIR waveband which is widely used for interpretation of remotely sensed data. Soil line based vegetation indices are introduced which may be used for assessment of water use, plant stress, crop production and requires knowledge of external environment. Slope, intercept of soil line were developed for four different series and used for estimation of vegetative indices. The maximum slope for soil line was for Targaon series followed by Rahuri, Pather and Gulvanch series. Relationships between bulk density and vegetation indices (RVI, SAVI) were developed by curve fitting method, linear function was most suitable function. Relationship between vegetation indices (SAVI and RVI) and bulk density was developed which can be used for determination of physical properties from remotely sensed data.

- KEY WORDS : Reflectance, Soil line, Vegetation indices

- HOW TO CITE THIS PAPER : Raut, S.S. and Gavit, B.K. (2015). Development of soil line and vegetative indices using spectroradiometer. Internat. J. Agric. Engg., 8(2) : 227-231. 